\title{
Research Article \\ The Stability of a Movable High-Strength Inverted-Triangular Steel Bridge
}

\author{
Lei Gao $\mathbb{D}$, Linyue Bai $\mathbb{D}^{\mathbb{D}}$, Kebin Jiang $\mathbb{D}$, Qiang Wang $\mathbb{D}$, and Xiaohui He
}

Army Engineering University of PLA, Field Engineering Institute, Nanjing 210007, China

Correspondence should be addressed to Qiang Wang; qwangjx@sina.com

Received 15 June 2018; Revised 20 August 2018; Accepted 27 August 2018; Published 19 September 2018

Academic Editor: Ricardo Branco

Copyright ( 2018 Lei Gao et al. This is an open access article distributed under the Creative Commons Attribution License, which permits unrestricted use, distribution, and reproduction in any medium, provided the original work is properly cited.

\begin{abstract}
The overall stability of a movable high-strength inverted-triangular steel bridge is worth studying because of its new truss structure. In this study, an approach was proposed based on the stiffness equivalence principle in which the inverted-triangle truss structure was modeled as a thin-walled triangular beam. On this basis, the calculation of the critical load of elastic stability of a movable highstrength inverted-triangular steel bridge with variable rigidity at both ends and locally uniformly distributed load was carried out based on the energy theory, which was in good agreement with existing theories. A material performance test at BS700 was carried out to establish the material properties, and then a finite element model of the bridge was established, the results of which were compared with those of the experimental load test, in order to verify the accuracy of the finite element model. Considering material nonlinearity and geometric nonlinearity, nonlinear buckling analysis of the bridge was conducted and the factors influencing the bridge's ultimate bearing capacity were analyzed.
\end{abstract}

\section{Introduction}

High-strength steel with a yield strength of 460-690 MPa has been commonly used in construction projects in Japan, the United States, and some other countries [1-3]. In addition, the $1100 \mathrm{MPa}$-level high-strength steel has been used in some military bridges, such as FB48. Over the past few years, an increasing number of high-strength steel buildings have been built in China [4-6], with Q420 and Q460 as the main two types of high-strength steel being used. According to the research, the application of high-strength steel can effectively contribute to self-weight reduction and cost saving [6], which has made it more suitable for the design of movable emergency bridges. This is the reason why high-strength steel with a yield strength greater than $700 \mathrm{MPa}\left(\sigma_{0.2} \geq 700 \mathrm{MPa}\right)$ is used in some movable bridges [7]. Movable high-strength inverted-triangular steel bridges developed with BS700 highstrength steel $\left(\sigma_{0.2}=700 \mathrm{MPa}\right)$ are a new type of long-span bridge whose length and deck load can reach $51 \mathrm{~m}$ and 60 ton, respectively. This kind of bridge consists of two side bridge segments with variable cross-sections and four identical central bridge segments.
Apart from BS700 high-strength steel, a new invertedtriangular truss structure was used in this bridge. Two pieces of inverted-triangular truss structures made up two lanes, which were connected and integrated in between on the top using cross beams. Central bridge segments are shown in Figure 1. Normally, a rectangular truss system is used in a truss bridge, yet research findings suggested that a triangular treadway bridge performs better in saving materials and reducing weight than a rectangular truss bridge [8]. Meanwhile, the triangular truss was usually employed on a limited basis for a number of structures such as roof truss girders, transmission towers, and crane booms [9]. In some composite bridges the triangular trusses were also widely used [10]. The mentioned triangular trusses were usually vertically triangular, but an inverted-triangular truss system emerged with the development of long-span spatial structures [11]. Today the inverted-triangular truss is more commonly applied in composite bridges [12, 13]. Inverted-triangular trusses were used in the movable bridge designed in this study. To make it convenient for mechanized bridging, there 


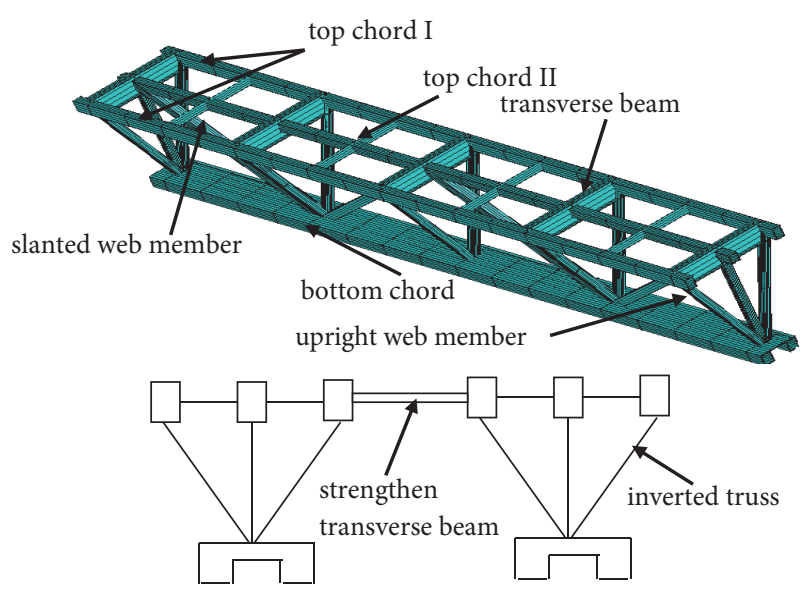

FIgURE 1: The members of a typical bridge segment.

was no connection to the bottom chord, and the top chord was also weakly connected, which offers a promising area for further studies on the bridge's overall stability.

Considerable research on the stability of triangular or inverted-triangular truss structures has been done. The eigenvalue stability of truss structures was studied through critical point theory $[14,15]$. Some laboratory-scale tests and fullscale testing of old steel truss tests were performed to get the load-carrying capacity of truss structures $[16,17]$. A full-scale triangular composite truss structure specimen was tested and compared with finite element analysis [13], and the finite element model (FEM) was validated with experimental results. Recently the truss bridge's linear buckling analysis and nonlinear stability analysis, which can consider material nonlinearity and initial geometric defects, were both done by the finite element method [18-20]. The stability ultimate load influence factors of truss structures were also studied. It was found that the joint rigid connection has more influence on the ultimate bearing capacity of triangular space-truss structure [21]. Height-width ratio has more influence on the integral stability and the proposed height-width ratio is $0.75 \sim 0.875$ [22]. In comparison with the paper that has already been published, the main purpose of this work is to investigate the stability of a novel high-strength invertedtriangular steel truss bridge that has varied sections in its side bridge segments. In this study, the elastic stability of the movable inverted-triangular steel bridge was analyzed theoretically, and a calculation equation was obtained to predict its elastic load-carrying capacity. The material performance test of BS700 and the field test of load-carrying capacity were conducted. The bridge's elastic stability load-carrying capacity was calculated using the finite element method and compared with the theoretical result. Both material nonlinearity and geometric nonlinearity were considered in analyzing the nonlinear stability of the bridge by the finite element method. Moreover, factors influencing the stability load-carrying capacity of the movable high-strength inverted-triangular steel bridge were analyzed.

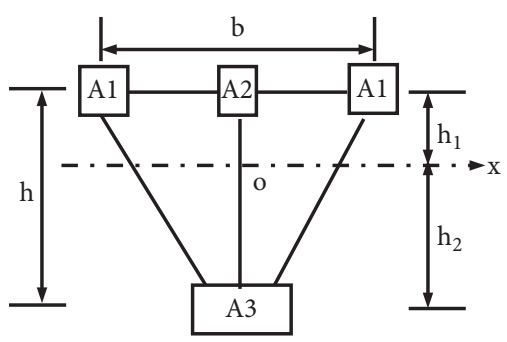

FIGURE 2: Schematic diagram of the cross section of the movable high-strength inverted-triangular steel bridge.

\section{Analysis of Elastic Stability Load-Carrying Capacity}

Analysis of the elastic stability load-carrying capacity lays the foundation for analyzing the nonlinear stability loadcarrying capacity. To perform the theoretical analysis, the truss structure is usually modeled as a beam, following the principle of equivalent stiffness [23]. In terms of the truss structure of a movable high-strength inverted-triangular steel bridge, the stiffness parameters are mainly axial rigidity $E A$, in-plane flexural rigidity $E I_{x}$, out-plane flexural rigidity $E I_{y}$, and torsional rigidity $G I_{k}$.

\subsection{Simplification to Thin-Walled Triangular Beam Based} on Equivalent Stiffness. The simplified diagram of the cross section of the movable high-strength inverted-triangular steel bridge is shown in Figure 2.

There are two different sections on the top chord whose areas are $A_{1}$ and $A_{2}$. The area of the bottom chord is $A_{3}$. The position of a section centroid is determined according to $S_{x}=0$. Supposing that point $o$ is the centroid and $h_{1}$ and $h_{2}$ are the distances between the centroid and the top and bottom chords, then

$$
\begin{aligned}
& h_{1}=\frac{A_{3} h}{2 A_{1}+A_{2}+A_{3}} \\
& h_{2}=\frac{\left(2 A_{1}+A_{2}\right) h}{2 A_{1}+A_{2}+A_{3}} .
\end{aligned}
$$

The equivalent area is

$$
A=2 A_{1}+A_{2}+A_{3} .
$$

Neglecting the contribution of the component's cross section to the overall moment of inertia moment of inertia, the equivalent moment of inertia is

$$
\begin{aligned}
& I_{x}=\left(2 A_{1}+A_{2}\right) h_{1}^{2}+A_{3} h_{2}^{2}, \\
& I_{y}=\frac{1}{2 A_{1} b^{2}} .
\end{aligned}
$$

Therefore, the axial rigidity $E A$, in-plane equivalent flexural rigidity $E I_{x}$, and out-plane flexural rigidity $E I_{y}$ could be calculated, respectively. In terms of torsional rigidity $G I_{k}$, since the web member connecting the chord primarily bears 


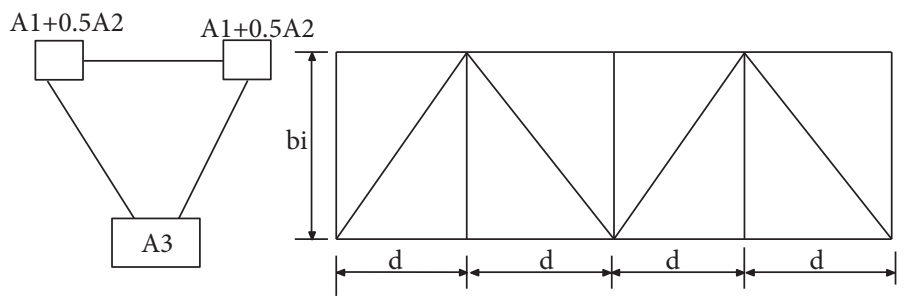

FIGURE 3: Schematic diagram of the movable high-strength inverted-triangular steel bridge.

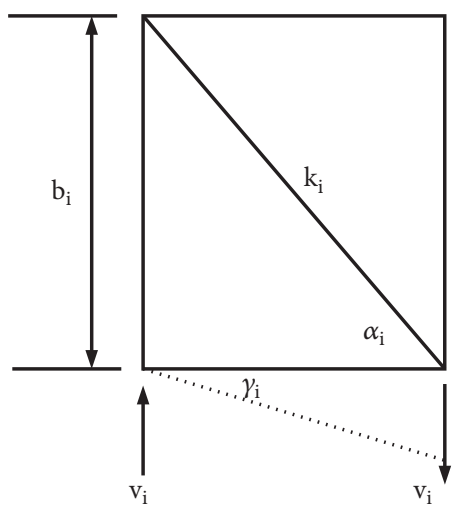

FIGURE 4: One segment of the movable high-strength invertedtriangular steel bridge.

the shear force, its contribution to torsion could not be ignored. There are two types of web members used in the movable high-strength inverted-triangular steel bridge: one is connected to the bottom and top chord I and the other is connected to the bottom chord and top chord II (Figure 1). For simplification, the middle chord (top chord II) and web member are evenly distributed to both sides, forming two sections of trusses on the left and right sides (Figure 3 ).

One section of the movable high-strength invertedtriangular steel bridge is taken as a calculation unit and converted into a thin plate whose thickness is te at each side. The whole section to be calculated is converted into a thinwalled triangular beam, with its torsion strength calculated. If the intersegment length is $d$ and height is $b_{i}$, according to the equation of strain energy density, the strain energy of each piece of thin plate $i$ is

$$
U_{e i}=\frac{q^{2} d}{2 G} \sum_{i=1}^{3} \frac{b_{i}}{t e_{i}} .
$$

The thickness $t e_{i}$ can be determined based on the condition that strain energy $U_{i}$ and $U_{e i}$ of a truss with a length of $\mathrm{d}$ are equal. Suppose the total shear force that results from shear flow $q$ acting upon the truss plane is $V_{i}=q b_{i}$. A segment of the bridge is taken as the research object, as shown in Figure 4.

The internal force generated by a slanted web member with the action of shear force is

$$
D=\frac{V_{i}}{\sin \alpha_{i}}=V_{i} \frac{k_{i}}{b_{i}}=q b_{i} \frac{k_{i}}{b_{i}}=q k_{i} .
$$

If the length and area of the web member are $l$ and $A$, and it bears a constant force $P$, its strain energy is

$$
\Delta u=\frac{P^{2} l}{2 E A}
$$

The chord's axial force varies linearly within the length of $l$. Assuming the maximum force $S=1 / 2 q d$, the chord's strain energy is

$$
\Delta u=\frac{1}{2 E A} \int_{0}^{l}\left(S-\frac{2}{l} S x\right)^{2} d x=\frac{S^{2} l}{6 E A} .
$$

The strain energy of each piece of truss unit with a length of $d$ can be obtained according to (6) and (7):

Top chord:

$$
\Delta u_{0}=\frac{q^{2} d^{3}}{24 E A_{0}}
$$

where $A_{0}=A_{1} / 2+A_{2} / 4$.

Slanted web member:

$$
\Delta u_{d}=\frac{q^{2} k^{3}}{2 E A_{d}}
$$

where $A_{d}=A_{d 1} / 2$ and $A_{d 1}$ is the area of central slanted web member.

Bottom chord:

$$
\Delta u_{u}=\frac{q^{2} d^{3}}{24 E A_{u}}
$$

where $A_{u}=A_{3} / 2$.

Vertical web member:

$$
\Delta u_{v}=\frac{q^{2} d^{3}}{2 E A_{v}}
$$

where $A_{v}$ is the area of the slanted web member.

The equation for the $i^{t h}$ piece of truss unit could be calculated by summing up the strain energy of the aforementioned four chords and web members:

$$
\begin{aligned}
u_{t i} & =\Delta u_{o i}+\Delta u_{u i}+\Delta u_{v i} \\
& =\frac{q^{2}}{2 E}\left[\frac{d^{3}}{12}\left(\frac{1}{A_{o i}}+\frac{1}{A_{u i}}\right)+\frac{k^{3}}{A_{d i}}+\frac{b_{i}^{3}}{A_{v i}}\right] .
\end{aligned}
$$

The following equation is obtained according to the principle of equal strain energy: 


$$
\frac{q^{2}}{2 E}\left[\frac{d^{3}}{12}\left(\frac{1}{A_{o i}}+\frac{1}{A_{u i}}\right)+\frac{k^{3}}{A_{d i}}+\frac{b_{i}^{3}}{A_{v i}}\right]=\frac{q^{2} d}{2 G} \frac{b_{i}}{t_{e i}} .
$$

Then, the thickness of equivalent thin-walled beam is

$$
t_{e i}=\frac{E}{G} \frac{b_{i} d}{\left(d^{3} / 12\right)\left(1 / A_{o i}+1 / A_{u i}\right)+k^{3} / A_{d i}+b_{i}^{3} / A_{v i}} .
$$

At this point, the converted thicknesses of the triangle's three sides, $t_{e 1}, t_{e 2}$, and $t_{e 3}$, are calculated. The equivalent torsion moment of inertia is obtained according to the constant equation of free torsion of a thin-walled closed section of arbitrary shape [24].

$$
I_{k}=\frac{4 A_{0}^{2}}{\oint(d s / t)}=\frac{4 A_{0}^{2}}{S_{1} / t_{e 1}+S_{2} / t_{e 2}+S_{3} / t_{e 3}}
$$

where $A_{0}$ is the area of the closed section formed by the medians of the thin-walled triangle; $S_{1}, S_{2}$, and $S_{3}$ are the widths of three thin-walled plates, i.e., lengths of the three sides of the triangle's cross section; and $t_{e 1}, t_{e 2}$, and $t_{e 3}$ are the converted thicknesses of three sides. $G I_{k}$, the torsional rigidity of the thin-walled triangular beam simplified from the movable high-strength inverted-triangular steel bridge, can be obtained based on (14) and (15).

The equivalent rigidity can be calculated using MATLAB according to this theoretical derivation [25]. Due to the fact that the rigidities of both end units of the movable highstrength inverted-triangular steel bridge are variable while the central rigidity remains unchanged, two programs are compiled to calculate their respective equivalent rigidities, which can be calculated by entering the bridge's height and width and the sizes of various chords and bars into the programs. With this calculation, the moments of area of the sections where central rigidity remained unchanged were $I_{x}=0.0096 m^{4}, I_{y}=0.0018 m^{4}$, and $I_{k}=0.000163 m^{4}$.

2.2. Critical Load of Linear-Elastic Stability. It is difficult to find the solution to the torsional rigidity if the movable highstrength inverted-triangle steel bridge is simplified into a thin-walled triangular beam, since the bridge's rigidity varies at the two ends while the central rigidity stays the same. To this end, it is solved using the energy method [24]. The axial compressive strain energy and shear strain energy are too low to be taken into account. In addition, a study made by Liu [23] suggests that the warping strain energy of a thin-walled triangular beam is negligible. This strain energy contains lateral bending strain energy $U_{1}$, in-plane bending strain energy $U_{2}$, and pure torsion strain energy $U_{3}$.

Lateral bending strain energy can be obtained according to the strain energy equation [24].

$$
U_{1}=\frac{1}{2} \int_{0}^{l} E I_{y}\left(u^{\prime \prime}\right)^{2} d z
$$

In-plane bending strain energy is

$$
U_{2}=\frac{1}{2} \int_{0}^{l} E I_{x}\left(v^{\prime \prime}\right)^{2} d z
$$

Free torsion strain energy is

$$
U_{3}=\frac{1}{2} \int_{0}^{l} G I_{k}\left(\phi^{\prime}\right)^{2} d z
$$

where $u$ is the lateral displacement, $v$ is the vertical displacement, and $\varphi$ is the torsion angle.

Therefore, total strain energy is

$$
\begin{aligned}
U & =U_{1}+U_{2}+U_{3} \\
& =\frac{1}{2} \int_{0}^{l} E I_{y}\left(u^{\prime \prime}\right)^{2}+G I_{k}\left(\phi^{\prime}\right)^{2}+E I_{x}\left(v^{\prime \prime}\right)^{2} d z .
\end{aligned}
$$

Chen [24] reported that the flexural bars' elastic flexuraltensional buckling critical flexural moment was increased to some extent by the effect of large counter-arch due to flexural deformation. Therefore, ignoring the impact of inplane flexure would result in a slightly smaller critical load and a more conservative result. Equation (19) is thus reduced to

$$
U=U_{1}+U_{2}+U_{3} \approx \frac{1}{2} \int_{0}^{l} E I_{y}\left(u^{\prime \prime}\right)^{2}+G I_{k}\left(\varphi^{\prime}\right)^{2} d z .
$$

Without considering residual stress, the potential energy of external force can be calculated with the following equation when any section is subjected to the combined action of axial force and flexural moment [24].

$$
W=\frac{1}{2} \int_{0}^{l} 2 \beta_{y} M_{x}\left(\varphi^{\prime}\right)^{2}+2 M_{x} u^{\prime \prime} \varphi d z
$$

The potential energy of the external force should be (21) combined with the strain energy generated by the changes of the load's action spot. Supposing the distance between the load's action spot and shearing center is a (Figure 5), the potential generated is

$$
\Delta W=-\frac{1}{2} \int_{0}^{l} q_{z} a \varphi^{2} d z .
$$

Hence, the total potential energy of the external force is

$$
W=\frac{1}{2} \int_{0}^{l} 2 \beta_{y} M_{x}\left(\varphi^{\prime}\right)^{2}+2 M_{x} u^{\prime \prime} \varphi d z-q_{z} a \varphi^{2} d z
$$

where $\beta_{y}=\int_{A} y\left(x^{2}+y^{2}\right) d A / 2 I_{x}-y_{0}$ is the section asymmetry coefficient and $\beta_{y}=-y_{0}$ because the section is symmetrical. $y_{0}$ is the distance between the shearing center and the centroid. According to our calculation, $\beta_{y}=-0.2, a=$ 0.17 .

Total potential energy is

$$
\begin{aligned}
\Pi & =\frac{1}{2} \int_{0}^{l} E I_{y}\left(u^{\prime \prime}\right)^{2}+G I_{k}\left(\phi^{\prime}\right)^{2} d z+2 \beta_{y} M_{x}\left(\phi^{\prime}\right)^{2} \\
& +2 M_{x} u^{\prime \prime} \phi d z-q_{z} a \phi^{2} d z .
\end{aligned}
$$

The integral of the total potential energy should be taken in segments as the height of the movable high-strength invertedtriangular steel bridge varies linearly at both ends and the 


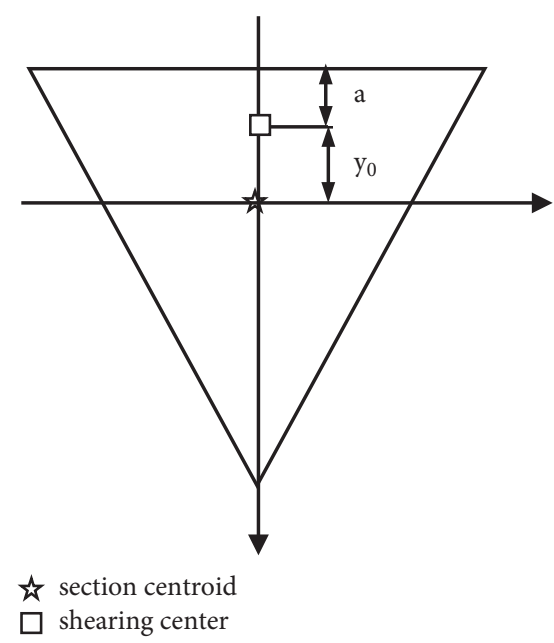

FIgURE 5: Position of the shearing center of the movable high-strength inverted-triangular steel bridge.

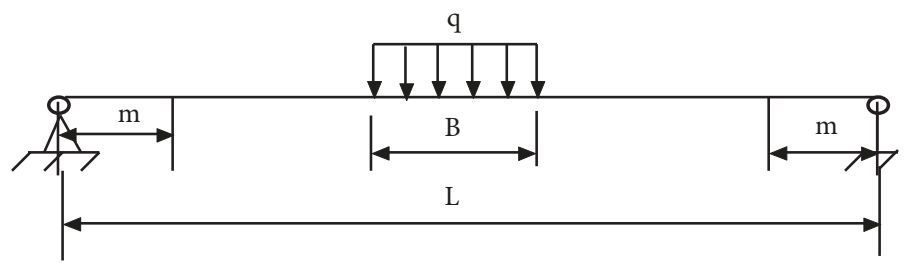

Figure 6: Thin-walled triangular beam under locally uniformly distributed load.

uniformly distributed load acts locally upon the mid-span (Figure 6). Due to the linear variation of height, supposing the flexural rigidity and torsional rigidity are also subject to linear variations, the maximum rigidities are $I_{y_{2}}$ and $I_{k 2}$, respectively, and the minimum rigidities are $I_{y 1}$ and $I_{k 1}$, respectively. Assume the width of the local uniformly distributed load, the length of the segment with variable rigidity, the intensity of uniformly distributed load, and the span of the simply supported bridge are $B, m, q$, and $L$, respectively.

The expressions of segmented load and rigidity are shown as follows.

Uniformly-distributed load : $q_{\mathrm{z}}$

$$
= \begin{cases}0 & 0 \leq z \leq \frac{(L-B)}{2} \\ q & \frac{(L-B)}{2}<z \leq \frac{(L+B)}{2} \\ 0 & \frac{(L+B)}{2}<z \leq L\end{cases}
$$

Flexural moment of inertia : $\mathrm{I}_{\mathrm{y}}$

$$
= \begin{cases}\mathrm{I}_{y 1}+\frac{I_{y 2}-I_{y 1}}{m} & 0 \leq z \leq m \\ I_{y 2} & m<z \leq L-m \\ \frac{I_{y 1}-I_{y 2}}{m} z-\frac{L\left(I_{y 1}-I_{y 2}\right)-m I_{y 1}}{m} & L-m<z \leq L\end{cases}
$$

Torsion moment of inertia : $\mathrm{I}_{\mathrm{k}}$

$$
= \begin{cases}\mathrm{I}_{k 1}+\frac{I_{k 2}-I_{k 1}}{m} & 0 \leq z \leq m \\ I_{k 2} & m<z \leq L-m \\ \frac{I_{k 1}-I_{k 2}}{m} z-\frac{L\left(I_{k 1}-I_{k 2}\right)-m I_{k 1}}{m} & L-m<z \leq L\end{cases}
$$

Flexural moment : $M_{x}$

$$
= \begin{cases}\frac{(q B) z}{2} & 0 \leq z \leq \frac{(L-B)}{2} \\ \frac{q B z}{2}-\frac{q[z-(L-B) / 2]^{2}}{2} & \frac{(L-B)}{2}<z \leq \frac{(L+B)}{2} \\ \frac{q B z}{2}-q B\left(z-\frac{L}{2}\right) & \frac{(L+B)}{2}<z \leq L\end{cases}
$$

Therefore, the integral of total potential energy is performed on five intervals along the beam's lengthwise direction; namely,

$$
\begin{gathered}
{[0, m] ;\left[m, \frac{(L-B)}{2}\right] ;\left[\frac{(L-B)}{2}, \frac{(L+B)}{2}\right] ;} \\
{\left[\frac{(L+B)}{2}, L-m\right] ;[L-m, L] .}
\end{gathered}
$$

The Rayleigh-Ritz method is used to solve the critical flexural moment [21]. Suppose the shape function that matches the boundary conditions is 


$$
\begin{aligned}
& u=c_{1} \sin \frac{\pi z}{L}, \\
& \varphi=c_{2} \sin \frac{\pi z}{L} .
\end{aligned}
$$

Total potential energy is

$$
\begin{aligned}
\Pi= & \frac{1}{2} \int_{0}^{l} \frac{\pi^{4} E I_{y}}{L^{4}} c_{1}^{2} \sin ^{2} \frac{\pi z}{L}+G I_{k} \frac{\pi^{2}}{L^{2}} c_{2}^{2} \\
& +2 \beta_{y} M_{x} \frac{\pi^{2}}{L^{2}} c_{2}^{2} \cos ^{2} \frac{\pi z}{L}-2 M_{x} \frac{\pi^{2}}{L^{2}} c_{1} c_{2} \sin ^{2} \frac{\pi z}{L} \\
& -q_{z} a c_{2}^{2} \sin ^{2} \frac{\pi z}{L} d z .
\end{aligned}
$$

After the segment integral, total potential energy is

$$
\begin{aligned}
\Pi & =\left\{f_{1} I_{y 1}+f_{2}\left(I_{y 2}-I_{y 1}\right)+f_{7} I_{y 2}+f_{11} I_{y 2}+f_{16} I_{y 2}\right. \\
& \left.+f_{22}\left(I_{y 1}-I_{y 2}\right)-f_{23}\left[L\left(I_{y 1}-I_{y 2}\right)-m I_{y 1}\right]\right\} c_{1}^{2} \\
& +\left\{f_{3} I_{k 1}+\left(I_{k 2}-I_{k 1}\right) f_{4}+q \beta_{y} f_{5}+I_{k 2} f_{8}+q \beta_{y} f_{9}\right. \\
& +f_{12} I_{k 2}+q \beta_{y} f_{13}-q a f_{15}+f_{17} I_{k 2}+q \beta_{y} f_{18} \\
& -q \beta_{y} f_{19}+f_{24}\left(I_{k 1}-I_{k 2}\right) \\
& \left.-f_{25}\left[L\left(I_{k 1}-I_{k 2}\right)-m I_{k 1}\right]+f_{26} q \beta_{y}-f_{27} q \beta_{y}\right\} c_{2}^{2} \\
& +q\left(-f_{6}-f_{10}-f_{14}-f_{20}+f_{21}-f_{28}+f_{29}\right) c_{1} c_{2}
\end{aligned}
$$

where $f_{1} \sim f_{29}$ are the parameters related to $L, B$, and $m$. have

According to the minimal potential energy principle, we

$$
\begin{aligned}
& \frac{\partial \Pi}{\partial c_{1}}=0, \\
& \frac{\partial \Pi}{\partial c_{2}}=0 .
\end{aligned}
$$

Three parameters are introduced:

$$
\begin{aligned}
K_{1}= & f_{1} I_{y 1}+f_{2}\left(I_{y 2}-I_{y 1}\right)+f_{7} I_{y 2}+f_{11} I_{y 2}+f_{16} I_{y 2} \\
& +f_{22}\left(I_{y 1}-I_{y 2}\right) \\
& -f_{23}\left[L\left(I_{y 1}-I_{y 2}\right)-m I_{y 1}\right] . \\
K_{2}= & f_{3} I_{k 1}+\left(I_{k 2}-I_{k 1}\right) f_{4}+q \beta_{y} f_{5}+I_{k 2} f_{8}+q \beta_{y} f_{9} \\
& +f_{12} I_{k 2}+q \beta_{y} f_{13}-q a f_{15}+f_{17} I_{k 2}+q \beta_{y} f_{18} \\
& -q \beta_{y} f_{19}+f_{24}\left(I_{k 1}-I_{k 2}\right) \\
& -f_{25}\left[L\left(I_{k 1}-I_{k 2}\right)-m I_{k 1}\right]+f_{26} q \beta_{y} \\
& -f_{27} q \beta_{y} . \\
K_{3}= & \left(-f_{6}-f_{10}-f_{14}-f_{20}+f_{21}-f_{28}+f_{29}\right) .
\end{aligned}
$$

The buckling condition of the equivalent thin-walled triangular beam is

$$
\left|\begin{array}{cc}
2 K_{1} & K_{3} \\
K_{3} & 2 K_{2}
\end{array}\right|=0
$$

To separate the load $q$ from the equation above, several coefficients, i.e., $z_{1}, z_{2}, z_{3}$, and $z_{4}$, are introduced:

$$
\begin{aligned}
z_{1}= & f_{3} I_{k 1}+\left(I_{k 2}-I_{k 1}\right) f_{4}+I_{k 2} f_{8}+f_{12} I_{k 2}+f_{17} I_{k 2} \\
& +f_{24}\left(I_{k 1}-I_{k 2}\right)-f_{25}\left[L\left(I_{k 1}-I_{k 2}\right)-m I_{k 1}\right] \\
z_{2}= & f_{5}+f_{9}+f_{13}+f_{18}-f_{19}+f_{26}-f_{27} \\
z_{3}= & f_{15} \\
z_{4}= & -f_{6}-f_{10}-f_{14}-f_{20}+f_{21}-f_{28}+f_{29} .
\end{aligned}
$$

The critical load is obtained:

$q_{c r}$

$$
=\frac{2 K_{1} \beta_{y} z_{2}-2 K_{1} a z_{3}+\sqrt{\left(2 K_{1} \beta_{y} z_{2}-2 K_{1} a z_{3}\right)^{2}+4 K_{1} z_{1} z_{4}^{2}}}{z_{4}^{2}} .
$$

To verify the correctness of this expression, a special circumstance, where load is uniformly distributed along the full span and rigidity remained unchanged along the beam's axial direction, was modeled. In this case, the critical load is as follows according to (42):

$$
\begin{aligned}
q_{c r} & =\frac{12 \pi^{2}}{\pi^{2}+3} \frac{\pi^{2} E I_{y}}{L^{4}}\left\{-\frac{6 a}{\pi^{2}+3}+\frac{\pi^{2}-3}{\pi^{2}+3} \beta_{y}\right. \\
& \left.+\sqrt{\left(-\frac{6 a}{\pi^{2}+3}+\frac{\pi^{2}-3}{\pi^{2}+3} \beta_{y}\right)^{2}+\frac{G I_{k} L^{2}}{\pi^{2} E I_{y}}}\right\} .
\end{aligned}
$$

According to Chen [24], the elastic critical flexural moment with full-span uniform load distribution is

$$
\begin{aligned}
M_{c r} & =\frac{3 \pi^{2}}{2\left(\pi^{2}+3\right)} \frac{\pi^{2} E I_{y}}{L^{2}}\left\{-\frac{6 a}{\pi^{2}+3}+\frac{\pi^{2}-3}{\pi^{2}+3} \beta_{y}\right. \\
& +\sqrt{\left(-\frac{6 a}{\pi^{2}+3}+\frac{\pi^{2}-3}{\pi^{2}+3} \beta_{y}\right)^{2}+\frac{I_{\omega}}{I_{y}}\left(1+\frac{G I_{k} L^{2}}{\pi^{2} E I_{\omega}}\right)} .
\end{aligned}
$$

Without considering warping the moment of inertia, the result of (43) is consistent with that of (44). Not considering the self-weight, the elastic critical load of the movable highstrength inverted-triangular steel bridge was $2300.6 \mathrm{kN}$, which was calculated by substituting the data obtained based on the strain energy principle into (43).

\section{Finite Element Analysis of Elastic Stability Load-Carrying Capacity}

To further verify the accuracy of the equation for the elastic stability ultimate load, a model was built using the finite element method to perform elastic buckling analysis. 
TABLE 1: MISO data used for ANSYS models.

\begin{tabular}{lccccccccc}
\hline Strain & 0.001 & 0.00178 & 0.00203 & 0.003 & 0.0037 & 0.00385 & 0.00426 & 0.00451 & 0.008 \\
\hline $\begin{array}{l}\text { Stress } \\
{[\mathrm{MPa}]}\end{array}$ & 209 & 370 & 419 & 592 & 689 & 704 & 734 & 754 & 790 \\
\hline
\end{tabular}

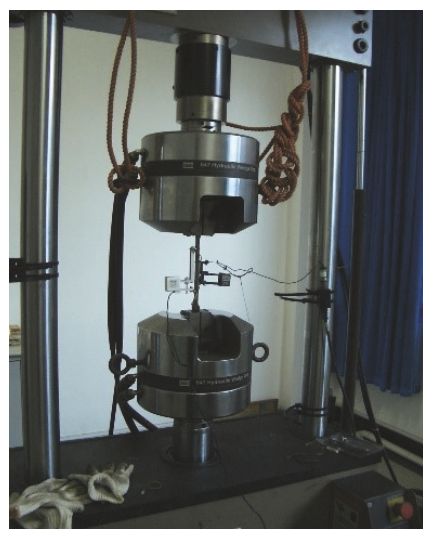

(a)

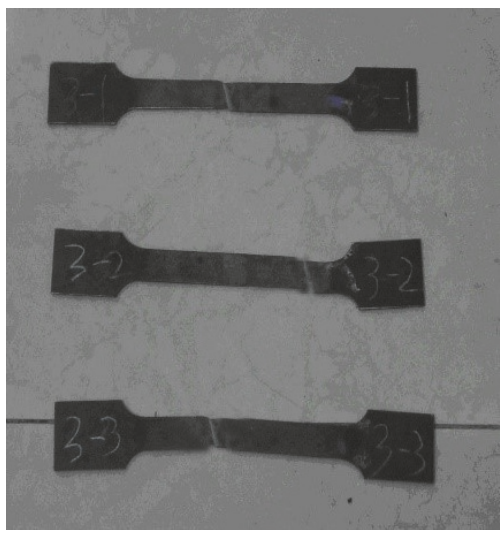

(b)

Figure 7: Material mechanical property test. (a) Test procedure. (b) The members' failure.

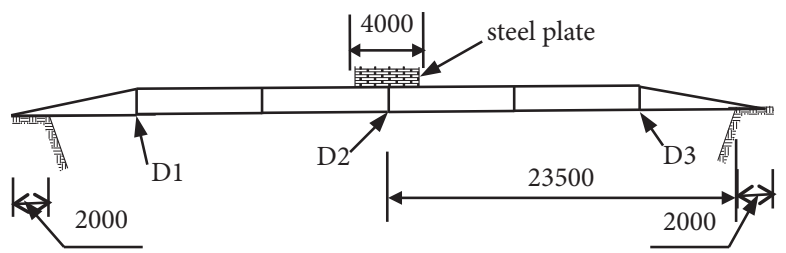

Figure 8: Diagram of test points and loading.

3.1. Establishment and Verification of the Finite Element Model. The beam element 188 of the ANSYS software, which can import a user's section data, was adopted in the finite element model. In order to analyze many modes used for studying the influence factors on stability ultimate load capacity, the model uses many parameters which can be easily changed in an APDL document (Analysis Parameter Design Language) [15]. The whole finite element model contains a basic model, eigenvalue buckling analysis, and the results of picking-up. The material model made use of the multilinear hardening model.

In order to get the material model data, uniaxial tension tests were carried out as shown in Figure 7(a). No obvious plastic flow or necking was observed in the tests. The failure planes were nearly placed along the $45^{\circ}$ cross section of the specimens as shown in Figure 7(b). Shear failure is dominant in the material.

As shown in Figure 7, the complete stress-strain curve of the BS700 steel is gently strain-hardening. According to the test data, the elastic modulus of the material is $210.9 \mathrm{GPa}$. The nominal yield stress $\sigma_{0.2}$ is $734 \mathrm{MPa}$ and the nominal yield strain $\varepsilon_{0.2}$ is 0.00426 . For the material model we chose the multilinear isotropic hardening (MISO) model. The MISO model needs points, as shown in Table 1.
3.2. Finite Element Model. In order to verify the basic finite element model validity, the load capacity test of the bridge was performed. A $51 \mathrm{~m}$-long bridge, where the bearing length at both ends was $2 \mathrm{~m}$ and clearance height under the span was $0.6 \mathrm{~m}$, was constructed. Two sections of planks were placed at the middle of bridge span to simulate two decks. Steel plates weighing $25.42 \mathrm{t} \longrightarrow 48.97 \mathrm{t} \longrightarrow 58.42 \mathrm{t} \longrightarrow 63.15 \mathrm{t} \longrightarrow 67.87$ $\mathrm{t} \longrightarrow 71.17 \mathrm{t} \longrightarrow 74.56 \mathrm{t} \longrightarrow 80.84 \mathrm{t}(1 \mathrm{t} \approx 10 \mathrm{kN})$ were loaded to and piled up on the planks. There were three deformation points at $L / 6,5 L / 6$, and $L / 2(L$ is $51 \mathrm{~m})$. Measuring points and the loading diagram of the test and field test images are shown in Figures 8 and 9 , respectively.

The test results compared with finite element analysis (FEA) results are shown in Table 2.

According to Table 2 it can be declared that the finite element model can simulate the bridge accurately; the errors were below $5 \%$, excepting a few points.

3.3. Eigenvalue Buckling Analysis. The typical equation for eigenvalue buckling analysis was [26]

$$
\left(\left[K_{0}\right]+\lambda\left[K_{\sigma}\right]\right)\{D\}=0
$$

where $\left[K_{0}\right]$ is the matrix of elastic rigidity; $\left[K_{\sigma}\right]$ is the matrix of stress rigidity; $\{D\}$ is the characteristic displacement vector; and $\lambda$ is the eigenvalue. 
TABLE 2: Comparison of the displacement results of the test points and FEM calculation.

\begin{tabular}{lccccccccc}
\hline $\begin{array}{l}p \\
{[\mathrm{kN}]}\end{array}$ & $u_{1}[\mathrm{~mm}]$ & $u s_{1}[\mathrm{~mm}]$ & $\frac{u s_{1}-u_{1}}{u_{1}} \%$ & $u_{2}[\mathrm{~mm}]$ & $u s_{2}[\mathrm{~mm}]$ & $\frac{u s_{2}-u_{2}}{u_{2}} \%$ & $u s_{3}[\mathrm{~mm}]$ & $u s_{3}[\mathrm{~mm}]$ & $\frac{u s_{3}-u_{3}}{u_{3}} \%$ \\
\hline 254.2 & 38 & 40 & 5.3 & 97 & 105 & 8.2 & 40 & 42 & 5.0 \\
489.7 & 73 & 78 & 6.8 & 202 & 211 & 4.5 & 80 & 83 & 3.6 \\
584.2 & 89 & 93 & 4.5 & 247 & 262 & 5.7 & 95 & 100 & 5.0 \\
631.5 & 95 & 100 & 5.3 & 272 & 282 & 3.5 & 105 & 108 & 2.8 \\
678.7 & 102 & 107 & 4.9 & 292 & 304 & 3.9 & 115 & 116 & 0.9 \\
711.7 & 107 & 112 & 4.7 & 312 & 319 & 2.2 & 120 & 121 \\
745.6 & 112 & 117 & 4.5 & 327 & 334 & 2.1 & 130 & 127 & -2.4 \\
808.4 & 122 & 127 & 4.1 & 342 & 362 & 5.5 & 135 & 138 \\
\hline
\end{tabular}

Note: $p$ is load, $u_{\mathrm{i}}$ is test deformation, $u s_{\mathrm{i}}$ is FEA calculation deformation, $\left(u s_{\mathrm{i}}-u_{\mathrm{i}}\right) / u_{\mathrm{i}}$ is ratio of FEA results to test results, and $\mathrm{i}=1,2,3$ represents the test points $\mathrm{D} 1, \mathrm{D} 2$, and D3.

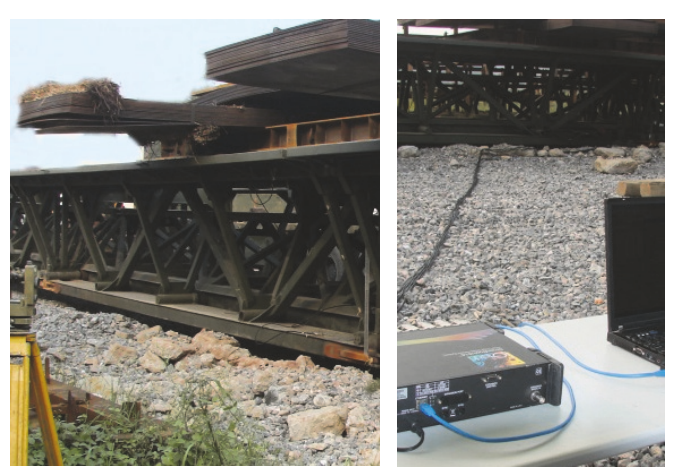

FIgure 9: The load test scene.

Without considering self-weight, the eigenvalue $\lambda$ obtained from eigenvalue buckling analysis multiplied by the load applied is the eigenvalue buckling load. In fact, the load kept changing, so that

$$
\left|\left[K_{0}\right]+\lambda\left[K_{\sigma}\right]\right|=0 .
$$

When the self-weight was not considered, the first-order eigenvalue buckling mode was obtained, as shown in Figure 10. The first-order eigenvalue buckling load was $2405.4 \mathrm{kN}$, which was $4.6 \%$ larger than the $2300.6 \mathrm{kN}$ load that was derived by the thin-walled beam equivalent theory in this study. This suggests a highly accurate value of the eigenvalue buckling load of the movable high-strength invertedtriangular steel bridge was derived in this study.

\section{Nonlinear Ultimate Bearing Capacity of the Bridge}

4.1. Theories on Nonlinear Analysis. Values of bridge's elastic ultimate bearing capacity obtained by theoretical derivation and eigenvalue buckling analysis were usually so large that they could only be used for qualitative analysis of the structure's load-carrying capacity instead of genuinely reflecting it. Therefore, nonlinear buckling analysis was required. Considering factors such as the structure's geometric defect and the nonlinearity of materials, a nonlinear buckling analysis was able to more truthfully present the structure's load-carrying capacity. In consideration of the material-geometry dual nonlinearity, the basic buckling equation could be converted into

$$
\left(\left[K_{0}\right]+\left[K_{\sigma}\right]+\left[K_{\varepsilon}\right]\right)\{U\}=\{P\}
$$

where $\left[K_{0}\right]$ is the small-displacement elastic stiffness matrix, $\left[K_{\sigma}\right]$ is the initial stress stiffness matrix, $\left[K_{\varepsilon}\right]$ is the large displacement elastic stiffness matrix, also known as the initial strain matrix, and $\{U\}$ and $\{P\}$ are nodal displacement and load vector, respectively. Solutions were found by means of the iteration method by gradually applying load increments. Structure stiffness changed as load rose. The structure reached its maximum load-carrying capacity when $\operatorname{det}\left(\left[K_{0}\right]+\right.$ $\left.\left[K_{\sigma}\right]+\left[K_{\varepsilon}\right]\right)=0$. Ultimate bearing capacity was tracked using the arc-length method.

4.2. Ultimate Bearing Capacity of the Bridge. The geometric deflection was introduced to the analysis model by the consistent-deflection-mode method, which simulates deflection distribution by the lowest buckling mode shape. The maximal displacement of buckling analysis was multiplied by a coefficient to amplify to the $1 / 1000$ span of bridge.

Based on the above finite element model and considering material and geometric dual nonlinearity factors, the stability ultimate load of the bridge can be obtained by using the arclength method [16]. Firstly, an elastic buckling analysis was performed when the load was $600 \mathrm{kN}$, and then the elastic buckling load, which was the top limit load of bridge, was found. Secondly, setting the elastic buckling load as the initial load, the accumulated loads were then introduced gradually until the solution was emanative. The load-displacement curve can be traced through time post-process (post 26). The highest point of the load-displacement curve reveals the stability ultimate load capacity of a movable high-strength inverted-triangular steel truss bridge. The load-displacement curves are shown in Figure 11.

From Figure 11 we can obtain the stability ultimate load capacity $\left(P_{u}\right)$ of the bridge, which is $1637.6 \mathrm{kN}$. The loaddisplacement curve is approximately linear, and the vertical displacement is bigger than the lateral displacement before the load arrives at the ultimate load capacity. Therefore, the 


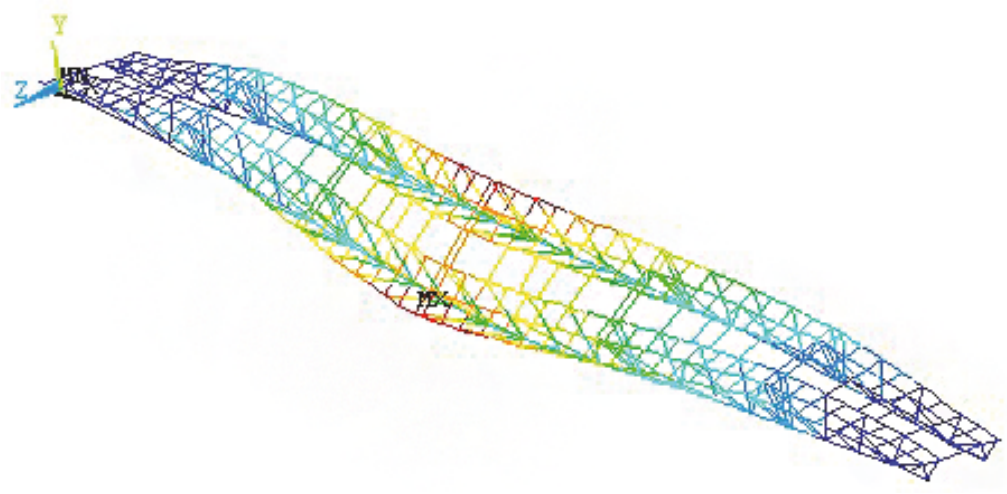

FIGURE 10: First-order eigenvalue buckling mode of the movable high-strength inverted-triangular steel bridge.

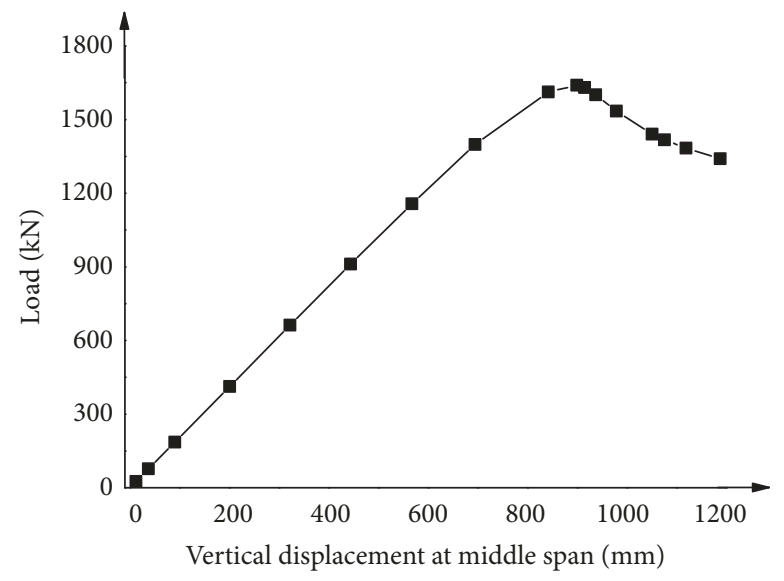

(a)

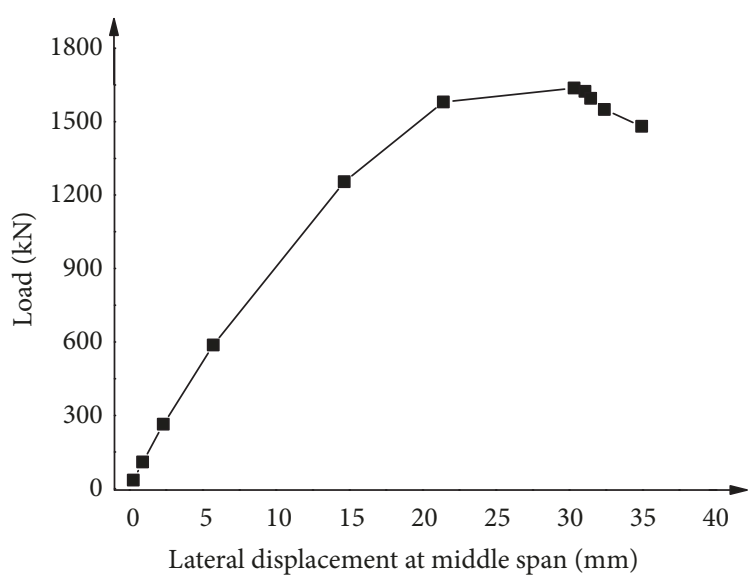

(b)

FIGURE 11: Load-displacement at middle span. (a) Load-vertical. (b) Load-lateral.

bridge's deformation is mainly in the moment plane; it is a kind of bending buckling when the load is small. When the load arrives at the stability ultimate load capacity of the bridge, the lateral deformation becomes bigger, and the bridge exhibits true bending-torsion buckling.

\section{Stability Ultimate Load Influence Factors Analysis}

There are many factors which can affect the stability ultimate load capacity of a movable high-strength inverted-triangular steel truss bridge, such as bridge span, bridge height, track width, and member's section. In order to study the influence of these factors on the stability ultimate capacity of the bridge, many FEA (finite element analysis) models with different parameters were analyzed.

5.1. Influence of Height and Track Width. The height and track width are two important parameters for design. When the analysis was performed, one parameter was changed each time. Through FEA analysis the stability ultimate load capacity $P_{u}$ was obtained. Based on the actual bridge's ultimate load capacity $P_{u}$ (which is $1637.6 \mathrm{kN}$ ) the change percentage can be determined $\left(P_{b}-P_{u}\right) / P_{u} \times 100$. The results are shown in Figure 12.

From Figure 12 a conclusion can be made that the height has more influence on the stability ultimate load capacity than the track width. The reason for this is that the bridge's height has more influence on section bending stiffness than track width does. Meanwhile, the track width changes but the whole bridge's width does not change; the lateral torsion stiffness changes a little. Thus, track width has less influence on the stability ultimate load capacity of the bridge.

5.2. Influence of Chord. The top and bottom chord are the important members in the bridge. How a chord influences the stability ultimate load was also studied in this paper. The top chord has two different box sections, which were labeled chord I and chord II. The top chord area changed at the same time of the width and height changes of the section. The multiplied area of the top chord can be found through adjusting the width and height of section gradually. The bottom chord is a kind of complex section. The multiplied area of the bottom chord can be found through adjusting the main dimensions of the section gradually. The results are shown in Figure 13. 


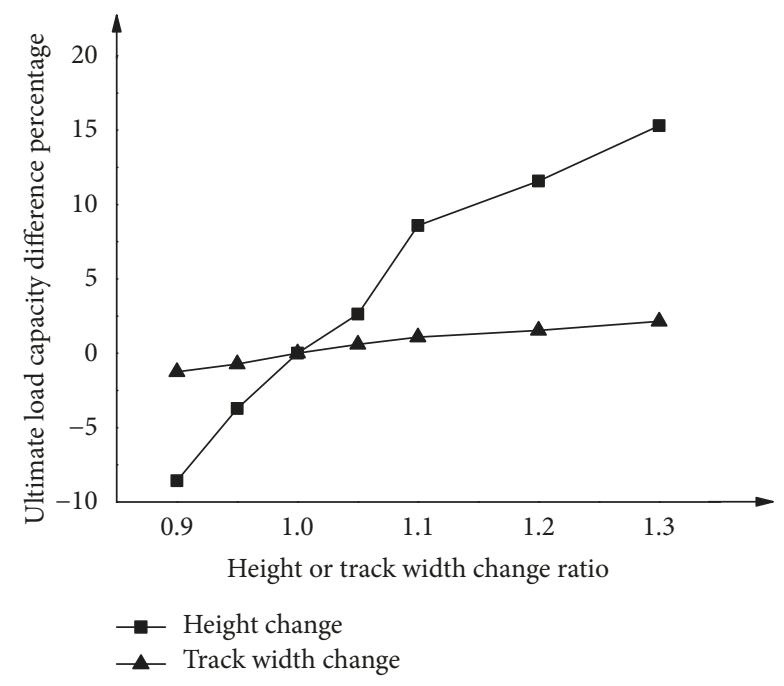

FIGURE 12: Change percentage of the bridge's ultimate load capacity when track width varies.

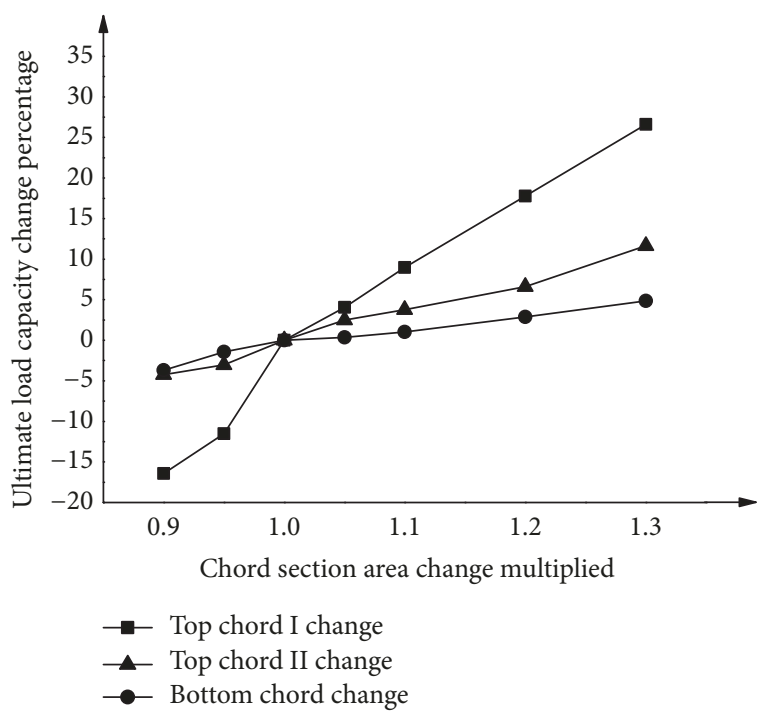

FIGURE 13: Change percentage of the bridge's ultimate load capacity when chord area varies.

From Figure 13 it can be concluded that the top chord has more influence on the stability load capacity than the bottom chord. The top chord I has more influence than chord II. The bottom chord has a little influence on the stability load capacity that changes below 5\%. Even top chord I has more influence than height when both two parameters change by the same percentage, as shown by comparing Figure 12 with Figure 13.

5.3. Influence of Web Member. The web member mainly bears shear force in the bridge structure but also provides some bending stiffness. There are two different web members shown in Figure 1, the sections of which are box shapes. Thus,

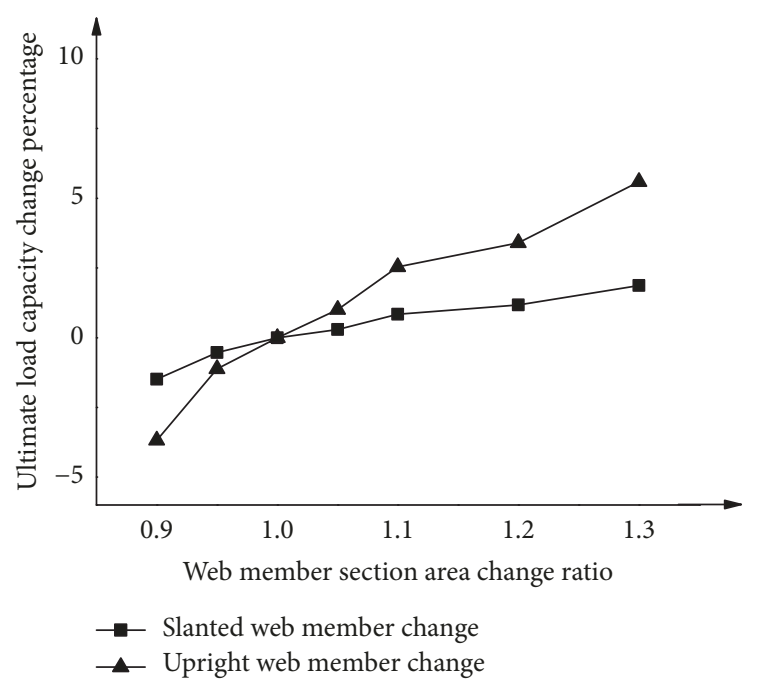

FIGURE 14: Change percentage of the bridge's ultimate load capacity when web member area varies.

the influence of the web member on the stability ultimate load was studied using the same method as the chord. The results are shown in Figure 14.

According to Figure 14, the web member has a little influence on the stability ultimate load capacity of the bridge. The influence of the upright web member is more than the slanted web member.

\section{Conclusions}

This paper investigated the stability of a movable highstrength inverted-triangular steel bridge by the theoretical, experimental, and finite element methods. From this study the following conclusions can be drawn:

(1) The movable high-strength inverted-triangular steel bridge can be modeled as equivalent to a thin-walled triangular beam according to the stiffness equivalence principle. The equivalent rigidities of the end units which are variable and the central units rigidity which remains unchanged were calculated.

(2) The equation which can calculate the elastic stability critical load of the inverted-triangular steel bridge with variable rigidities at both ends was put forward. This equation was well agreed with existing theoretical calculation. The calculated elastic stability load of the bridge was $2300.6 \mathrm{kN}$ by substituting equivalent rigidity into the equation.

(3) The material performance test of BS700 $\left(\sigma_{0.2}=700\right.$ $\mathrm{MPa}$ ) high-strength steel was carried out, and the material properties used for finite element analysis were obtained. The load capacity test of the movable high-strength invertedtriangular steel bridge whose length is $51 \mathrm{~m}$ was performed.

(4) A finite element model for the elastic buckling analysis of the movable high-strength inverted-triangular steel bridge was established. The finite element simulated results well agreed with field test results. The elastic buckling critical load of the bridge is $2405.4 \mathrm{kN}$, which further verifies the accuracy 
of the equation of the bridge's elastic stability critical load proposed in this study.

(5) The nonlinear buckling analysis model was put forward with consideration of material and geometric nonlinearity. The material model made use of the multilinear hardening model. The geometric deflection was introduced to the analysis model by the consistent-deflection-mode method. According to calculations, the bridge's ultimate bearing capacity is $1637.6 \mathrm{kN}$ which is lower than the elastic stability critical load.

(6) Analysis of factors influencing the bridge's ultimate bearing capacity suggests that top chord and bridge height are two major factors, of which top chord 1 exerts the dominant influence. Track width, bottom chord, and web member have less influence on the bridge's ultimate bearing capacity.

\section{Nomenclature}

EA: Axial rigidity

$E I_{x}:$ In-plane flexural rigidity

$E I_{y}$ : Out-plane flexural rigidity

$G I_{k}$ : Torsional rigidity

$A_{1}$ : The top chord I area

$A_{2}$ : The top chord II area

$A_{3}$ : The bottom chord area

$h_{1}$ : The distances between the centroid and the top chord

$h_{2}$ : The distances between the centroid and the bottom chord

$t e_{i}$ : The thickness of equivalent thin-walled beam

$d$ : The intersegment length

$b_{i}$ : The intersegment height

$U_{e i}$ : The strain energy of each piece of thin plate $i$

$V_{i}:$ The total shear force that results from shear flow $q$ acting upon the truss plane

$\Delta u_{0}$ : The top chord strain energy of each piece of truss unit

$\Delta u_{u}:$ The bottom chord strain energy of each piece of truss unit

$\Delta u_{v}$ : The vertical web member strain energy of each piece of truss unit

$u_{t i}$ : The total strain energy of the $i^{t h}$ truss unit

$U_{1}$ : Lateral bending strain energy

$U_{2}$ : In-plane bending strain energy

$U_{3}$ : Pure torsion strain energy

$U: \quad$ The total strain energy

$\Pi$ : $\quad$ Total potential energy

$u$ : The lateral displacement

$v$ : The vertical displacement

$\varphi$ : The torsion angle

$W$ : The potential energy of external force

$\beta_{y}$ : The section asymmetry coefficient

$a$ : The distance between the shearing center and the top side of equivalent thin-walled beam

B: The width of the local uniformly distributed load $m$ : The length of the segment with variable rigidity

q: $\quad$ The intensity of uniformly distributed load

L: $\quad$ The span of the simply supported bridge

$f_{1} \sim f_{29}: \quad$ The parameters related to $L, B$, and $m$

$c_{1}, c_{2}$ : The shape function parameters of the lateral displacement and the torsion angle

$K_{1}, K_{2}, K_{3}$ : The parameters related to $f, L, q$, $\beta_{y}, m, I_{y}$, and $I_{k}$

$z_{1}, z_{1} \sim z_{4}$ : The parameters related to $f, L, m$, and $I_{k}$

$q_{c r}: \quad$ The critical load

$\left[K_{0}\right]: \quad$ The small-displacement elastic stiffness matrix

$\left[K_{\sigma}\right]: \quad$ The initial stress stiffness matrix

$\left[K_{\varepsilon}\right]: \quad$ The initial strain matrix

$\{U\}: \quad$ Nodal displacement vector

$\{U\}: \quad$ Nodal load vector

$P_{u}: \quad$ The stability ultimate load capacity of the bridge.

\section{Data Availability}

(1) The bridge's height, width, sizes of various chords, and bars used to support the moments of area of the sections of this study are available from the corresponding author upon request. (2) The parameters related to $\mathrm{L}, \mathrm{B}$, and $\mathrm{m}$ used to support the elastic critical flexural moment of this study are available from the corresponding author upon request. (3) The material model used to support the stress-strain curve of BS700 steel of this study is currently under embargo while the research findings are commercialized. Requests for data, [12 months] after publication of this article, will be considered by the corresponding author. (4) 1/1000 span of bridge is the data used to support maximal displacement of buckling analysis of this study and is included within the article. It can be found in $[13,17]$.

\section{Conflicts of Interest}

The authors declare that there are no conflicts of interest regarding the publication of this paper.

\section{Acknowledgments}

The authors wish to acknowledge the financial support from the project of the Major State Basic Research Development of China (973 Program, No. 2014CB046801) and China Postdoctoral Science Foundation (Grant No. 2017M623403).

\section{References}

[1] Y. Fukumoto, "New constructional steels and structural stability," Engineering Structures, vol. 18, no. 10, pp. 786-791, 1996.

[2] G. A. Rosier and J. E. Groll, "High strength quenched and tempered steels in structures," Steel Construction, vol. 21, no. 3, p. 13, 1987.

[3] G. Pocock, "High strength steel use in Australia, Japan and the US," Structural Engineering International, vol. 84, no. 21, pp. 2730, 2006. 
[4] Z. M. Chen, Y. L. Zhang, and M. X. Peng, "Application of highstrength steel and thick steel plates to CCTV new site building," Steel Construction, vol. 24, no. 2, pp. 34-38, 2009.

[5] S. H. Zhou, Z. Y. Zhu, and W. H. Qi, "Structural design on the project of Phoenix International Media Center," Building Structure, vol. 41, pp. 56-62, 2001.

[6] G. Shi, H. Y. Ban, and Y. J. Shi, "Overview of research progress for high strength steel structures," Engineering Mechanics, vol. 30, no. 1, pp. 1-13, 2013.

[7] M. K. Gou and L. Tao, "The application of high strength steel (=700 MPa) to the movable bridge," Steel Structure, vol. 17, no. 5, p. 6, 2002.

[8] R. H. Durfee, "Design of a triangular cross section bridge truss," Journal of Structural Engineering, vol. 113, no. 5, pp. 2399-2414, 1987.

[9] R. H. Durfee, "Review of triangular cross section truss systems," Journal of Structural Engineering, vol. 112, no. 5, pp. 1088-1096, 1986.

[10] H. G. Dauner, A. Oribasi, and D. Wery, "The Lully viaduct, a composite bridge with steel tube truss," Journal of Constructional Steel Research, vol. 46, no. 1-3, pp. 67-68, 1998.

[11] G. E. Blandford, "Progressive failure analysis of inelastic space truss structures," Computer Structure, vol. 458, no. 4, pp. 981990, 1996.

[12] A. Reis and J. J. Oliveira Pedro, "Composite Truss Bridges: new trends, design and research," Steel Construction, vol. 4, no. 3, pp. 176-182, 2011.

[13] D. Zhang, Q. Zhao, F. Li, and Y. Huang, "Experimental and numerical study of the torsional response of a modular hybrid FRP-aluminum triangular deck-truss beam," Engineering Structures, vol. 133, pp. 172-185, 2017.

[14] G. H. Li, Bridge Stability and Vibration, Chinese Railway Press, Beijing, China, 1st edition, 2002.

[15] H. Sun, Y. Wang, and W. Zhao, "Comparison of theories for stability of truss structures. Part 1: Computation of critical load," Communications in Nonlinear Science and Numerical Simulation, vol. 14, no. 4, pp. 1700-1710, 2009.

[16] G. Brunell and Y. J. Kim, "Effect of local damage on the behavior of a laboratory-scale steel truss bridge," Engineering Structures, vol. 48, pp. 281-291, 2013.

[17] A. Azizinamini, "Full scale testing of old steel truss bridge," Journal of Constructional Steel Research, vol. 58, no. 5-8, pp. 843-858, 2002.

[18] Y. P. Tan and S. Q. Wang, "Buckling analysis of a long-span fast launching simple-supported bridge," Journal of Shenzhen University science \& engineering, vol. 18, no. 1, pp. 64-70, 2001.

[19] M. Tong, F. Mao, and H. Qiu, "Structural stability analysis for truss bridge," in Proceedings of the International Workshop on Automobile, Power and Energy Engineering, APEE 2011, pp. 546553, China, April 2011.

[20] B. Cheng, Q. Qian, and H. Sun, "Steel truss bridges with welded box-section members and bowknot integral joints, Part I: Linear and non-linear analysis," Journal of Constructional Steel Research, vol. 80, pp. 475-482, 2013.

[21] A. Fülöp and M. Iványi, "Experimentally analyzed stability and ductility behaviour of a space-truss roof system," Thin-Walled Structures, vol. 42, no. 2, pp. 309-320, 2004.

[22] F. N. Sun, Research on the integral stability of large span truss with inverted triangle section, Gui Zhou University, Guiyang, 2008.

[23] Y. S. Liu, Analysis for out-plane global stability of spatially latticed rigid frame with triangular section, Harbin Institute of Technology, Harbin, 2000.
[24] J. Chen, Stability of Steel Structures Theory and Design, Science Press, Beijing, China, 5th edition, 2011.

[25] X. M. Zhang, Matlab Language and Application Case, South-east University Press, Nanjing, China, 1st edition, 2010.

[26] C. H. Zhang, ANSYS 16.1 for the Analysis of Structure Engineering, China Machinery Press, Beijing, China, 4th edition, 2016. 


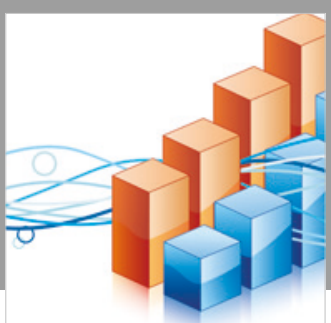

Advances in

Operations Research

\section{-n-m}
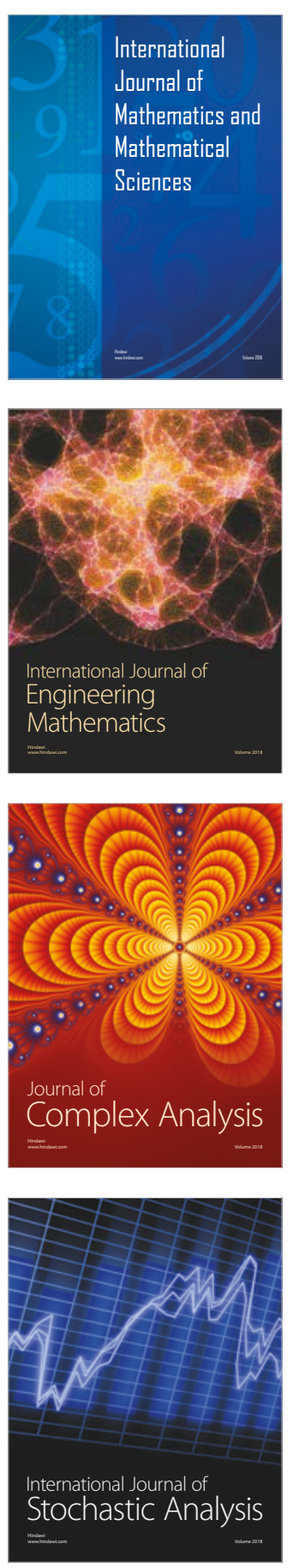
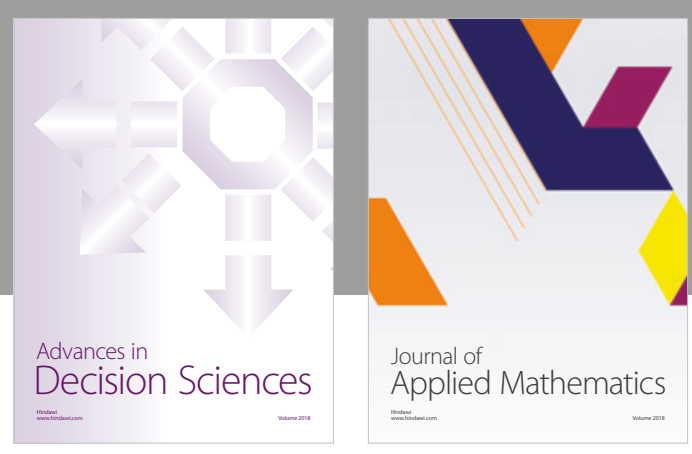

Journal of

Applied Mathematics
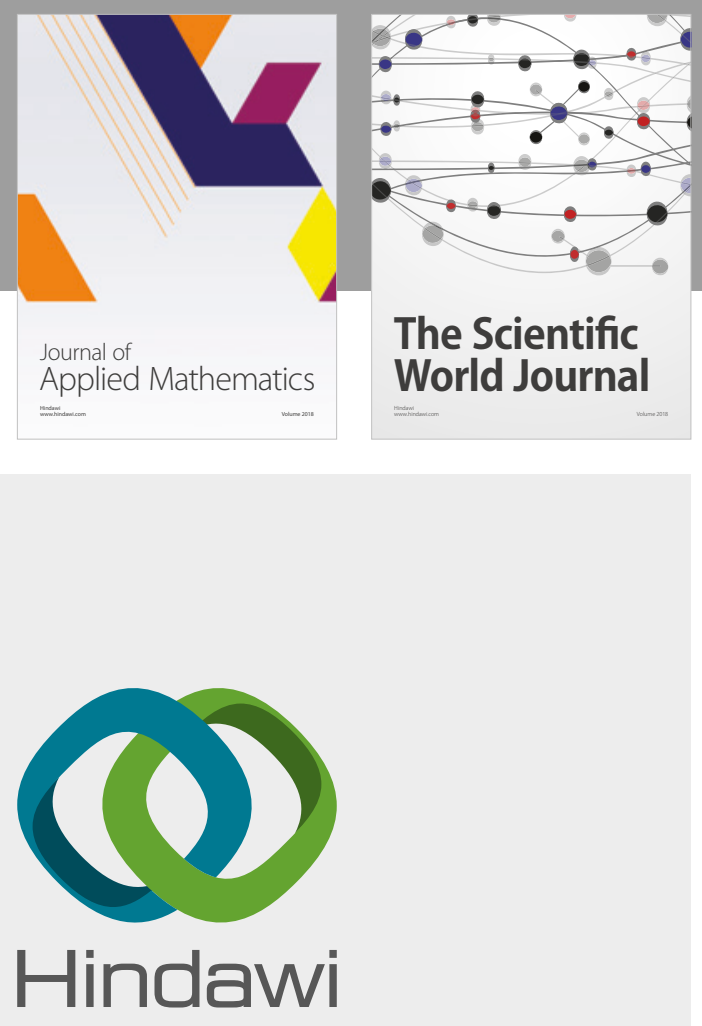

Submit your manuscripts at

www.hindawi.com

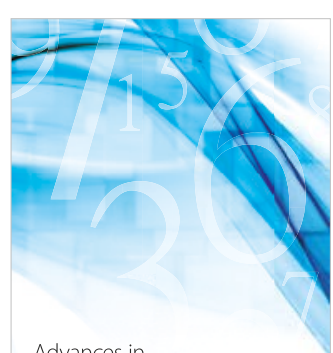

Advances in
Numerical Analysis
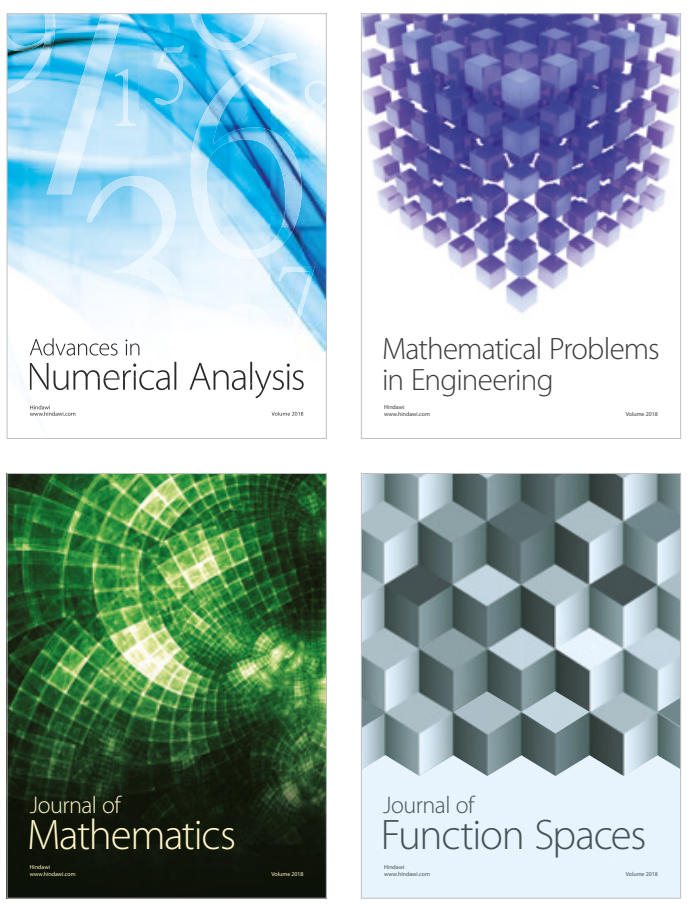

Mathematical Problems in Engineering

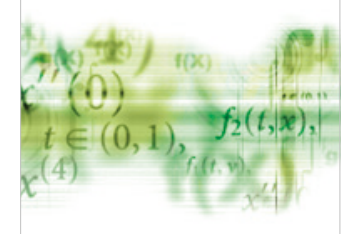

International Journal of

Differential Equations

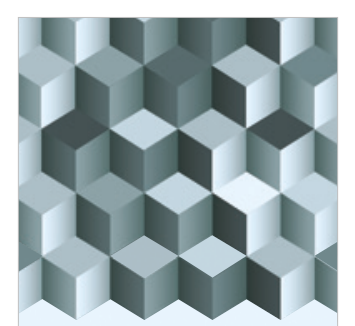

Journal of

Function Spaces

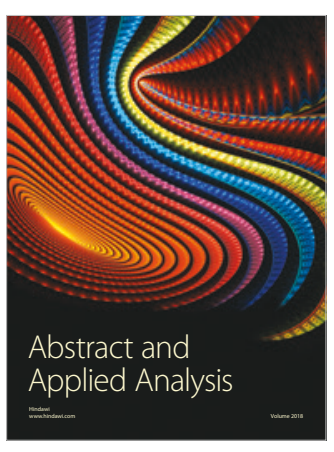

The Scientific

World Journal

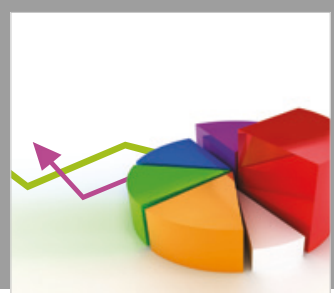

Journal of

Probability and Statistics
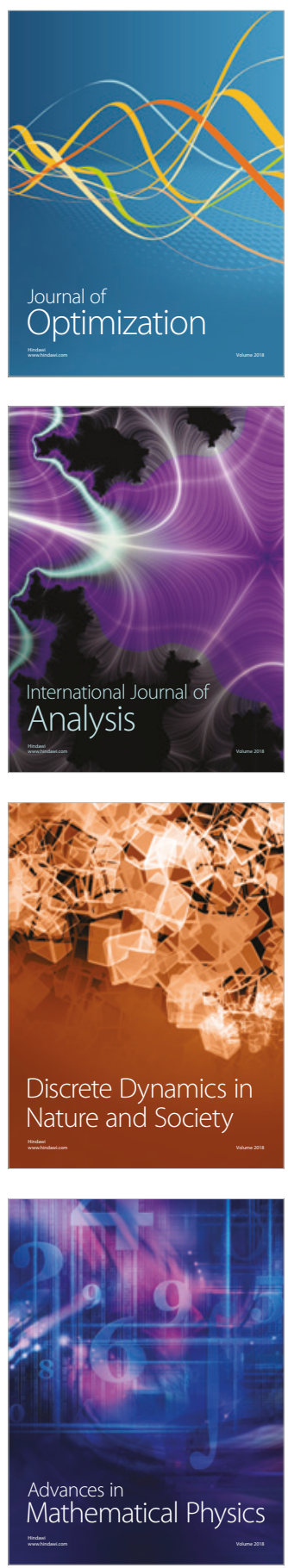